\title{
Electrochemical Surface Treatment of a $\beta$-titanium Alloy to Realize an Antibacterial Property and Bioactivity
}

\author{
Yusuke Tsutsumi ${ }^{1,2}, *$, Mitsuo Niinomi ${ }^{3}$, Masaaki Nakai ${ }^{3}$, Masaya Shimabukuro ${ }^{4}$, \\ Maki Ashida ${ }^{1}$, Peng Chen ${ }^{1}$, Hisashi Doi ${ }^{1}$ and Takao Hanawa ${ }^{1}$ \\ 1 Institute of Biomaterials and Bioengineering, Tokyo Medical and Dental University, Chiyoda, \\ Tokyo 101-0062, Japan; ashida.met@tmd.ac.jp (M.A.); chen.met@tmd.ac.jp (P.C.); doi.met@tmd.ac.jp (H.D.); \\ hanawa.met@tmd.ac.jp (T.H.) \\ 2 Graduate School of Engineering, The University of Tokyo, Bunyko, Tokyo 113-8656, Japan \\ 3 Institute for Materials Research, Tohoku University, Sendai, Miyagi 980-8577, Japan; \\ niinomi@imr.tohoku.ac.jp (M.N.); nakai@imr.tohoku.ac.jp (M.N.) \\ 4 Graduate School of Medical and Dental Sciences, Tokyo Medical and Dental University, Bunkyo, \\ Tokyo 113-0034, Japan; ma150039@tmd.ac.jp \\ * $\quad$ Correspondence: tsutsumi.met@tmd.ac.jp; Tel.: +81-3-5280-8009; Fax: +81-3-5280-8009 \\ Academic Editors: Vineet V. Joshi and Alan Meier \\ Received: 18 February 2016; Accepted: 24 March 2016; Published: 28 March 2016
}

\begin{abstract}
In this study, micro-arc oxidation (MAO) was performed on a $\beta$-type titanium alloy, namely, Ti-29Nb-13Ta-4.6Zr alloy (TNTZ), to improve not only its antibacterial property but also bioactivity in body fluids. The surface oxide layer formed on TNTZ by MAO treatment in a mixture of calcium glycerophosphate, calcium acetate, and silver nitrate was characterized using surface analyses. The resulting porous oxide layer was mainly composed of titanium oxide, and it also contained calcium, phosphorus, and a small amount of silver, all of which were incorporated from the electrolyte during the treatment. The MAO-treated TNTZ showed a strong inhibition effect on anaerobic Gram-negative bacteria when the electrolyte contained more than $0.5 \mathrm{mM}$ silver ions. The formation of calcium phosphate on the surface of the specimens after immersion in Hanks' solution was evaluated to determine the bioactivity of TNTZ with sufficient antibacterial property. As a result, thick calcium phosphate layers formed on the TNTZ specimen that underwent MAO treatment, whereas no precipitate was observed on TNTZ without treatment. Thus, the MAO treatment of titanium-based alloys is confirmed to be effective in realizing both antibacterial and bioactive properties.
\end{abstract}

Keywords: titanium alloy; micro-arc oxidation; antibacterial property; bioactivity; hard-tissue compatibility

\section{Introduction}

Titanium (Ti) and Ti alloys are widely used in both the orthopedic and dental fields because of their good mechanical properties, high corrosion resistance, and biocompatibility. In particular, $\beta$-type Ti alloys show a relatively low Young's modulus, and they have attracted attention for the development of novel metallic biomaterials that can reduce the stress-shielding effect of bone-fixating devices and increase the shock-absorbing property of dental implants. A $\beta$-type Ti alloy, Ti-29Nb-13Ta-4.6Zr (TNTZ), which is composed of non-toxic and non-allergenic elements, has been developed. It has a high potential for use in biomedical applications because of its excellent mechanical properties and low cytotoxicity along with a low Young's modulus [1,2]. In a previous study, the hard-tissue compatibility of TNTZ was evaluated in vivo [3]: The contact area of TNTZ with rabbit femur bone 
8 days after implantation was larger than that of Type 316 $\mathrm{L}$ stainless steel or conventional Ti-6Al-4V alloy. However, the bone tissue did not adhere to the entire TNTZ area. Therefore, it was necessary to enhance the hard-tissue compatibility and bioactivity of TNTZ. One of the most used methods is micro-arc oxidation (MAO), sometimes also called plasma electrolytic oxidation (PEO), and it is known as a useful surface treatment based on electrochemical reactions under high voltage in a specific electrolyte. Both in vitro [4] and in vivo [5] evaluations have revealed that MAO treatment improves the hard-tissue compatibility of Ti. MAO treatment is also suitable for valve metals because a porous oxide layer is easily achieved by the competing growth and breakdown of the oxide with a high-electric resistance layer under high voltage. As a result, the MAO treatment easily alters the surface properties of metals and is effective in improving the bioactivity of valve metals. The bioactivity of the materials can be evaluated by observation of spontaneous calcium phosphate formation on their surface during immersion in simulated body fluids containing both calcium and phosphate ions [6-12]. In our latest study, it was found that the bioactivity of TNTZ could be improved by MAO [13]. The MAO-treated TNTZ showed a drastically enhanced calcium phosphate formation in Hanks' solution. We also found that the component elements such as calcium $(\mathrm{Ca})$ and phosphorus $(\mathrm{P})$ in the electrolyte were incorporated into the resultant porous oxide layer by MAO treatment $[13,14]$.

In recent years, biofilm formation because of bacterial adhesion and colonization on biomaterials has been recognized as a major cause of failure in implant surgeries [15-18]. Once the biofilm is formed and firmly adhered to the implanted material, the bacterial secretion plays a pestiferous role as a barrier against the host's defense mechanism. Thus, pathogens are difficult to eliminate once a biofilm has formed on a device implanted in a living body. In serious cases, there is no way to remove the contaminated devices from the patient and to prevent subsequent undesirable biological reactions such as infection diseases. The easiest strategy to prevent the formation of biofilms on metallic devices is polishing, because a roughened surface is known to enhance bacterial adhesion. It was reported that the increase in the surface area and the formation of pockets enhanced harboring of bacteria $[19,20]$. However, for metallic implant devices such as dental implants and orthodontic fixators used in contact with bone, a roughened surface is always preferred for hard-tissue compatibility. Another way to prevent biofilm formation is the application of antibacterial agents. Silver (Ag) ion is known as one of the most effective agents because it exhibits superior antibacterial properties [21-24]. Surface modification enables the formation of a biofunctional layer supporting $\mathrm{Ag}$, as a source of $\mathrm{Ag}$ ion is expected to overcome the problems caused by biofilm formation on metallic biomaterials.

Therefore, in this study, MAO treatment was considered for surface modification to introduce Ag onto metallic biomaterials. TNTZ was MAO-treated in an electrolyte containing Ag ions for incorporating $\mathrm{Ag}$ into the resulting porous oxide layer. Surface analyses were performed to investigate the effects of $\mathrm{Ag}$ on the structure and the composition of the oxide layer. Then, the antibacterial property was evaluated by bacterial adhesion test using anaerobic Gram-negative bacteria. Bioactivity was also evaluated by both qualitative and quantitative analyses of calcium phosphate formation after immersion in Hanks' solution for seven days to reaffirm the efficacy of MAO treatment, even in the presence of Ag. We focused on demonstrating whether it is possible to achieve both an antibacterial and bioactive property on the Ti alloy by the one-step simple electrochemical treatment.

\section{Materials and Methods}

\subsection{Specimen Preparation}

Specimens were prepared from a hot-forged and cold-rolled bar of TNTZ. After mechanical processing, TNTZ was subjected to a solution treatment at $1063 \mathrm{~K}$ for $3.6 \mathrm{ks}$ in vacuum followed by water quenching. The $8 \mathrm{~mm}$ (for surface characterization and bioactivity evaluation) and $25 \mathrm{~mm}$ (for antibacterial property evaluation) diameter TNTZ disks were obtained by cutting the heat-treated rod. The surfaces of the disks were mechanically grinded using up to \#800 grid $\mathrm{SiC}$ abrasive paper, 
followed by ultrasonic cleaning in acetone and ethanol. These specimens were kept in an auto-dried desiccator until the following treatment.

\subsection{MAO Treatment}

The TNTZ specimen was fixed in a polytetrafluoroethylene holder with an o-ring. The exposed area in contact with the electrolyte was $39 \mathrm{~mm}^{2}$ (7.0 $\mathrm{mm}$ in diameter) or $398 \mathrm{~mm}^{2}$ (22.5 mm in diameter). Details of the working electrode are described elsewhere [25]. A Type-304 stainless steel plate was used as a counter electrode. The base composition of the electrolyte for MAO treatment was $100 \mathrm{mM}$ calcium glycerophosphate and $150 \mathrm{mM}$ calcium acetate. In this study, 0 to $5 \mathrm{mM}$ silver nitrate $\left(\mathrm{AgNO}_{3}\right)$ was also added to the electrolyte for incorporation of $\mathrm{Ag}$ into the oxide layer formed by MAO treatment. After pouring the electrolyte into the electrochemical cell, both electrodes were connected to a DC power supply (PL-650-0.1, Matsusada Precision Inc., Shiga, Japan), and then, a positive voltage, with the adjustment of the constant current density condition of $251 \mathrm{~A} \cdot \mathrm{m}^{-2}(9.8 \mathrm{~mA}$ and $100.0 \mathrm{~mA}$ for $39 \mathrm{~mm}^{2}$ and $398 \mathrm{~mm}^{2}$ specimens, respectively), was applied for $10 \mathrm{~min}$. Thus, the major part of the specimen was MAO-treated with an annular untreated area, $0.5 \mathrm{~mm}$ from the edge. All the surface characterizations described below were performed within the MAO-treated area.

\subsection{Surface Characterization and Bioactivity Evaluation}

The surface morphologies of the specimens were analyzed using a scanning electron microscope (SEM, S-3400NX, Hitachi High-Technologies Corp., Tokyo, Japan).

The chemical compositions of the specimens were analyzed using $X$-ray fluorescence spectrometer (XRF, XGT-1000WR, HORIBA Ltd., Kyoto, Japan). Quantitative analyses of the XRF results were performed using the fundamental parameter method with standard samples.

Bioactivity was evaluated by immersion in simulated body fluids in general. A SBF solution [26] is recognized as the most common fluid for bioactive evaluation. In this study, Hanks' solution without glucose was used because of more adequate judgement on intricately-structured surface. The composition of the solution is shown in Table 1. Perfluoroalkoxy alkane bottles were washed with nitric acid and rinsed with ultra-pure water in advance. Specimens were immersed in bottles with $40 \mathrm{~mL}$ of Hanks' solution at $37^{\circ} \mathrm{C}$ for 7 days. The solution was replaced with a fresh one 3.5 days after the first immersion. The amount of calcium phosphate precipitated on the specimens was determined by the following method. Reagent-grade nitric acid (60\%-61\%) and ultra-pure water were mixed with a volume ratio of 1:99. Specimens were immersed and stirred in the nitric acid solution to completely dissolve the precipitated calcium phosphate. Inductively coupled plasma atomic spectrometer (ICP-AES, ICPS-7000 ver.2, Shimadzu Corp., Kyoto, Japan) was used to determine the concentrations of both $\mathrm{Ca}$ and $\mathrm{P}$ ions in the solution. Prior to the measurement, standard solutions of $\mathrm{Ca}$ and $\mathrm{P}$ ions with concentrations of $0.01,0.1$, and 1 ppm were also prepared.

Table 1. Composition of Hanks' solution used in this study $\left(\mathrm{mol} \cdot \mathrm{L}^{-1}\right)$.

\begin{tabular}{cccccccc}
\hline $\mathbf{N a}^{+}$ & $\mathrm{K}^{+}$ & $\mathbf{M g}^{2+}$ & $\mathbf{C a}^{2+}$ & $\mathbf{C l}^{-}$ & $\mathbf{H P O}_{4}{ }^{2-}$ & $\mathbf{S O}_{4}{ }^{2-}$ & $\mathbf{C O}_{3}{ }^{2-}$ \\
\hline $1.42 \times 10^{-1}$ & $5.81 \times 10^{-3}$ & $8.11 \times 10^{-4}$ & $1.26 \times 10^{-3}$ & $1.45 \times 10^{-1}$ & $7.78 \times 10^{-4}$ & $8.11 \times 10^{-4}$ & $4.17 \times 10^{-3}$ \\
\hline
\end{tabular}

\subsection{Bacterial Adhesion Test}

To evaluate the antibacterial property of the MAO-treated specimen, the bacterial adhesion test was performed with anaerobic Gram-negative bacterium (Escherichia coli, NBRC3972, NITE, Tokyo, Japan) in accordance with the standard test method (ISO 22196:2011). The suspension medium was prepared by a five-hundred fold dilution of the nutrient broth containing $3 \mathrm{gL}^{-1}$ meat extract, $10 \mathrm{gL}^{-1}$ peptone, and $5 \mathrm{gL}^{-1}$ sodium chloride. The $\mathrm{pH}$ of the suspension medium was adjusted to be between 6.8 and 7.2 with sodium hydroxide or hydrochloric acid. The bacteria were added to the suspension medium to obtain $5 \times 10^{6}$ colony forming units $(\mathrm{CFU}) \mathrm{mL}^{-1}$. The bacterial suspension of volume 
$0.1 \mathrm{~mL}$ was dropped onto a specimen and a cover film was placed immediately. The specimens and the cover films were incubated at $35{ }^{\circ} \mathrm{C}$ for $24 \mathrm{~h}$; then, they were washed using $9.9 \mathrm{~mL}$ of sterile physiological saline. The CFU of the living bacteria dispersed into the saline was determined using the culture medium sheet for E. coli (JNC Corp., Tokyo, Japan).

Three specimens were used in each treatment conditions. Statistical analyses were performed using Student's t test (two-tailed) with $p<0.05$ considered statistically significant.

\section{Results and Discussion}

\subsection{Surface Properties after MAO Treatment}

Figure 1 shows the SEM images of TNTZ before and after MAO treatment. The untreated TNTZ showed a relatively smooth surface and the grinding grooves could be observed in the higher magnification image. On the other hand, the MAO-treated specimens showed a typical structure of MAO-treated valve metals [14,27] reported in previous studies. The morphology of the porous oxide layer with a number of small holes less than $10 \mu \mathrm{m}$ in diameter was similar to MAO-treated TNTZ without Ag addition in the electrolyte, reported in our previous study [13]. Thus, it is supposed that the presence of $\mathrm{Ag}$ ions in the electrolyte does not influence the formation of the porous oxide layer during MAO treatment when the concentration of $\mathrm{AgNO}_{3}$ does not exceed $2.5 \mathrm{mM}$. However, when MAO treatment on TNTZ was tried with $5.0 \mathrm{mM} \mathrm{AgNO}_{3}$, the voltage was not increased completely and the micro-arc did not appear. This phenomenon might be derived from the change in the electrical resistance against the positive applied voltage of the oxide layer formed initially. Incorporation of excess Ag into the oxide layer altered its semiconducting property. As a result, the applied positive current was consumed only by the oxide evolution reaction that took place on the outermost surface of the oxide layer. Therefore, we set the concentration of $\mathrm{AgNO}_{3}$ added to the electrolyte for $\mathrm{MAO}$ treatment as a maximum of $2.5 \mathrm{mM}$ and performed the following investigation.
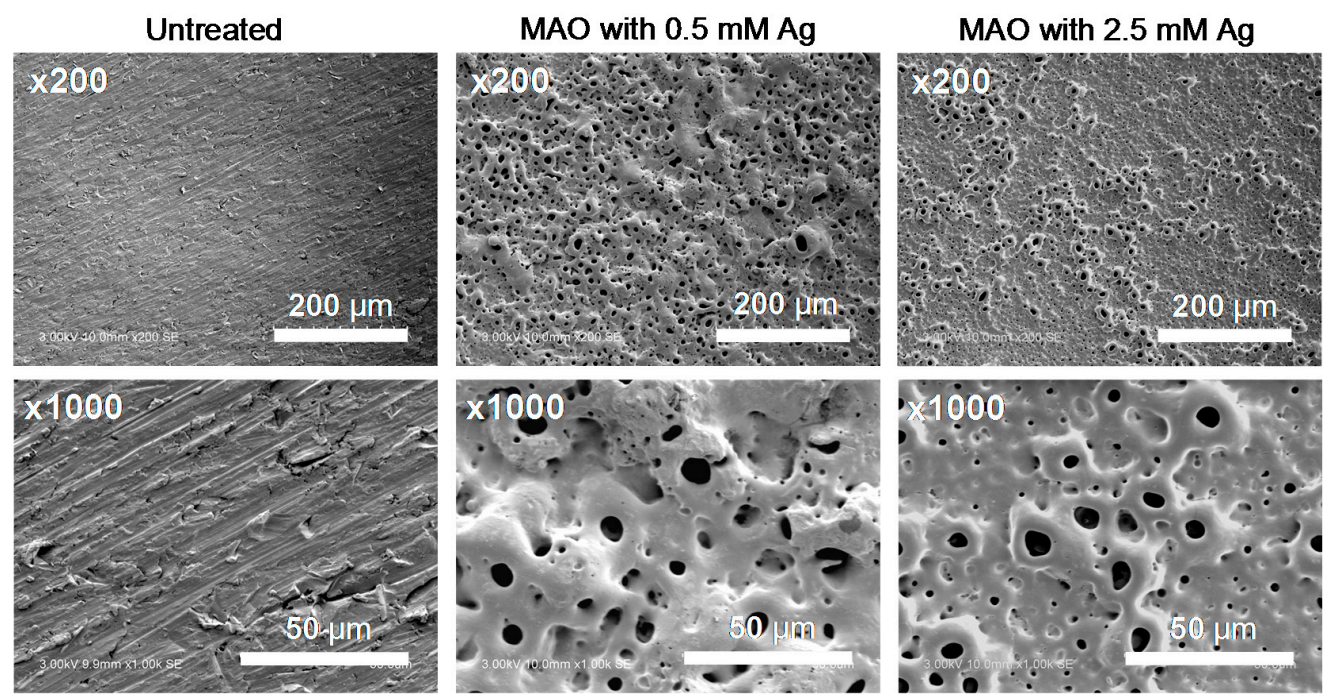

Figure 1. Scanning electron micrographs of TNTZ before and after MAO treatment.

The results of the XRF analyses are summarized in Table 2. In addition to the metal elements $(\mathrm{Ti}, \mathrm{Nb}, \mathrm{Ta}$, and $\mathrm{Zr}$ ), relatively high concentrations of $\mathrm{Ca}$ and $\mathrm{P}$ were detected from the porous oxide layer formed by MAO treatment. Thus, these elements were incorporated into the oxide layer during the rapid growth and breakdown of the oxide during MAO treatment. This incorporation of the electrolyte elements has been reported in our previous study $[13,14]$, as described in the introduction chapter. The concentrations of Ag in the MAO-treated samples were $0.01 \%$ and triple standard deviation, $3 \sigma$, were also $0.01 \%$. This implies that the concentration of Ag was almost equivalent to the 
detection limit of the measurement and the presence of Ag was still questionable. Figure 2 shows the $\mathrm{XRF}$ spectra of the fluorescence X-ray energy region of Ag K $\alpha$. Small peaks could be observed in the spectrum around $22.1 \mathrm{keV}$ for MAO-treated TNTZ with 0.5 and $2.5 \mathrm{mM} \mathrm{Ag}$, whereas no peaks were observed for untreated TNTZ. Thus, we confirmed the incorporation of Ag as well as Ca and P from the electrolyte in the oxide layer during MAO treatment. However, the amount of incorporated Ag was much lower than those of the incorporated $\mathrm{Ca}$ and $\mathrm{P}$ because of the difference in their original electrolyte concentrations: Ca was $250 \mathrm{mM}$, P was $150 \mathrm{mM}$, and Ag was $2.5 \mathrm{mM}$ maximum.

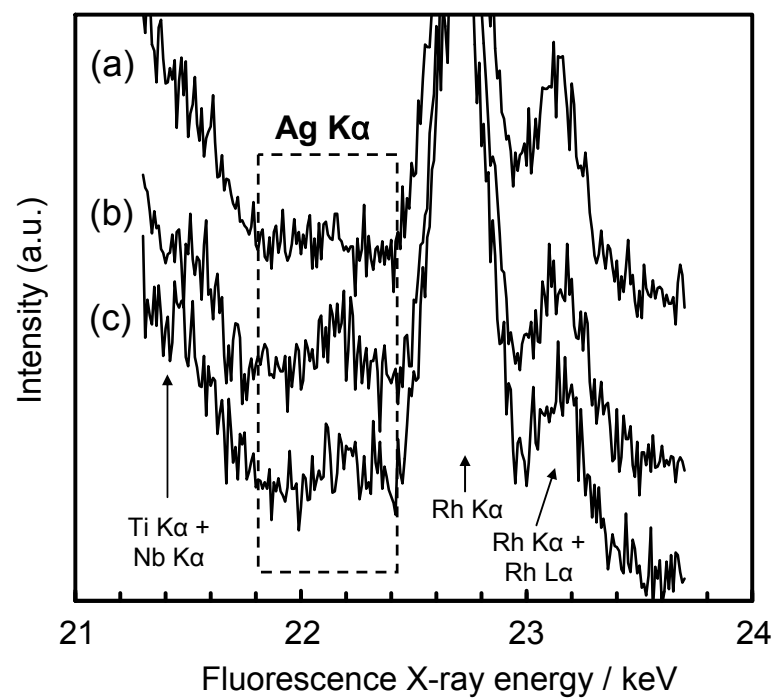

Figure 2. XRF spectra of (a) untreated, (b) MAO-treated with $2.5 \mathrm{mM} \mathrm{Ag}$, and (c) MAO-treated with $0.5 \mathrm{mM} \mathrm{Ag}$ around the $\mathrm{Ag} \mathrm{K} \alpha$ energy region.

Table 2. Concentrations of the detected elements by XRF on TNTZ specimen surfaces with/without MAO treatments.

\begin{tabular}{cccccccc}
\hline \multirow{2}{*}{ Specimen } & \multicolumn{7}{c}{ Concentration and triple standard deviation (in brackets), (mass\%) } \\
\cline { 2 - 8 } & $\mathbf{T i}$ & $\mathbf{N b}$ & $\mathbf{T a}$ & $\mathbf{Z r}$ & $\mathbf{C a}$ & $\mathbf{P}$ & $\mathbf{A g}$ \\
\hline \multirow{2}{*}{ Untreated } & 52.55 & 29.68 & 13.02 & 4.75 & & - & - \\
& $(0.06)$ & $(0.04)$ & $(0.05)$ & $(0.01)$ & & & \\
\hline MAO 2.5 & 35.46 & 28.86 & 11.07 & 4.63 & 9.33 & 10.65 & 0.01 \\
mM Ag & $(0.06)$ & $(0.04)$ & $(0.02)$ & $(0.01)$ & $(0.04)$ & $(0.06)$ & $(0.01)$ \\
\hline MAO 0.5 & 30.95 & 28.94 & 10.52 & 4.52 & 12.62 & 12.44 & 0.01 \\
mM Ag & $(0.07)$ & $(0.04)$ & $(0.04)$ & $(0.01)$ & $(0.07)$ & $(0.04)$ & $(0.01)$ \\
\hline \multicolumn{7}{c}{ Oxygen is exempted element for the equipment used in this study. }
\end{tabular}

\subsection{Antibacterial Property}

To precisely investigate the effect of Ag concentration on the antibacterial property of TNTZ, MAO-treated specimens with lower $\mathrm{AgNO}_{3}$ concentrations and Ag-free (treated with base electrolyte composition) specimens were also prepared. Figure 3 shows the result of the bacterial adhesion test. If the number of the bacteria is unchanged, $\mathrm{CFU} \mathrm{mL} \mathrm{m}^{-1}$ in Figure 3 counted from the mixture of the suspension and the saline can be calculated to be $5.0 \times 10^{4}$. Hence, the number of viable bacteria on untreated TNTZ did not change during 24-h incubation. In other words, mechanical grinding does not impart antibacterial property to TNTZ, as is the case of most metallic materials. On the other hand, the specimens treated with 0.5 and $2.5 \mathrm{mM} \mathrm{AgNO}_{3}$ showed no viable bacterium on their surface. Thus, the incorporated $\mathrm{Ag}$ in the porous oxide layer was quite effective against bacterial adhesion, and it could completely kill the bacteria within $24 \mathrm{~h}$ even though the concentration of Ag inside the porous oxide 
layer was minimal. The efficacy of Ag deteriorated when the concentration of $\mathrm{AgNO}_{3}$ was lowered. It was found that the threshold $\mathrm{AgNO}_{3}$ concentration for obtaining antibacterial property was around 0.05 to $0.5 \mathrm{mM}$ for TNTZ.

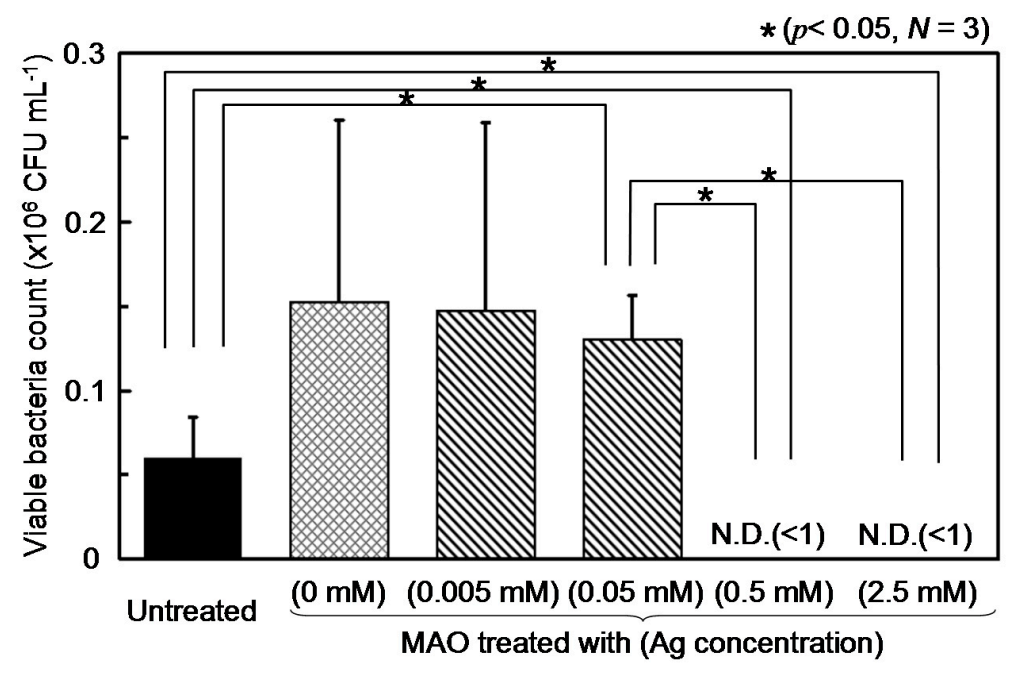

Figure 3. Result of bacterial adhesion test using E. coli on TNTZ specimens.

\subsection{Calcium Phosphate Formation in Hanks' Solution}

SEM images of the specimens after immersion in Hanks' solution for seven days are shown in Figure 4. There are almost no precipitates on the surface of untreated TNTZ specimens, and bare metal surface was still exposed even after immersion for seven days in simulated body fluid. On the other hand, MAO-treated TNTZ was completely covered by the newly formed precipitates or layers with apparent thickness. The cracks in the newly formed layer were observed on the specimen treated with $2.5 \mathrm{mM}$ Ag. It was confirmed that the cracks were introduced during the SEM observation process under vacuum because they were not observed just after electron beam irradiation.
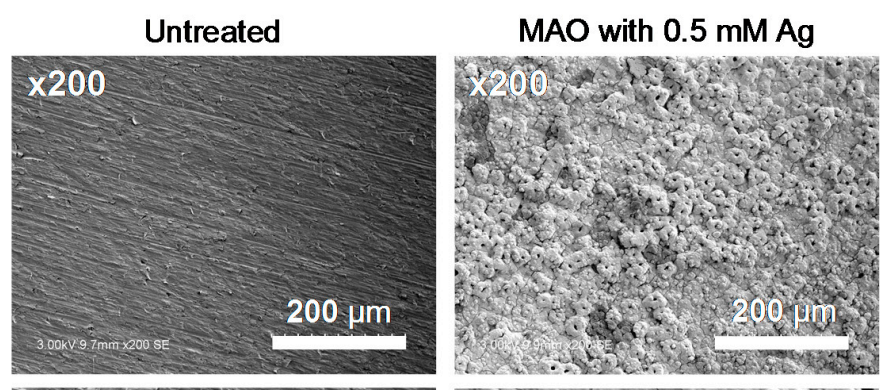

MAO with $2.5 \mathrm{mM} \mathrm{Ag}$
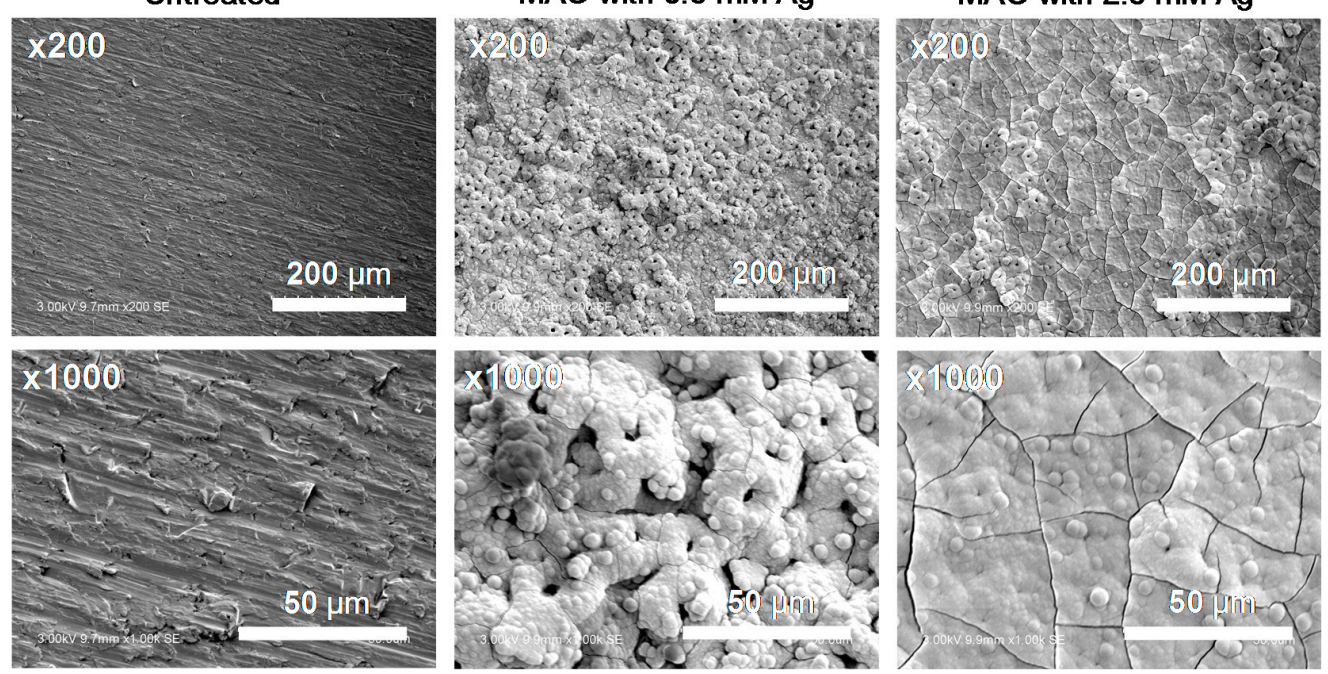

Figure 4. Scanning electron micrographs of specimens after immersion in Hanks' solution for 7 days.

Quantitative analysis was performed to determine the amount of Ca and P species formed on the specimen surface per unit area with ICP-AES. The results are summarized in Figure 5a. It is obvious that the amounts of $\mathrm{Ca}$ and $\mathrm{P}$ formed on the MAO-treated specimens were much higher than those 
formed on the untreated one. As shown in Figure 4, both the MAO-treated specimens were covered by newly formed precipitates. Thus, the precipitate on the MAO-treated specimens after immersion in Hanks' solution was confirmed to be spontaneously formed calcium phosphate.

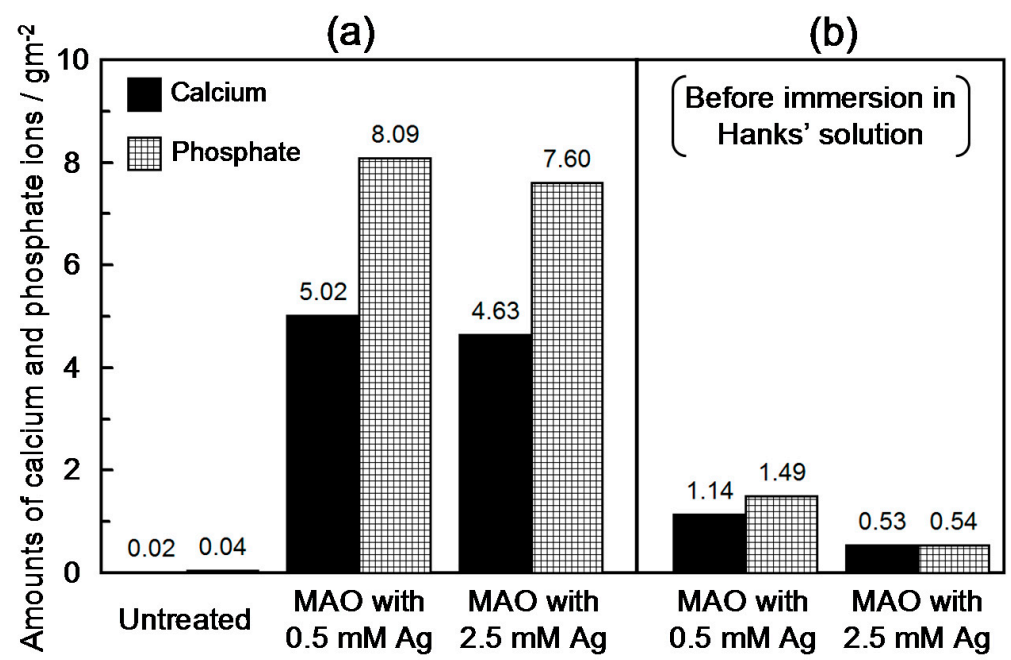

Figure 5. Amount of calcium and phosphate ions formed on TNTZ specimen surfaces in Hanks' solution determined by ICP-AES.

$\mathrm{Ca}$ and $\mathrm{P}$ were also detected from the MAO-treated specimen even before immersion in Hanks' solution (Table 2). To distinguish the $\mathrm{Ca}$ and $\mathrm{P}$ originating from the oxide layer as incorporated elements, the MAO-treated specimens before immersion in Hanks' solution were also tested in the same way.

The results are shown in Figure 5b. Certain amounts of $\mathrm{Ca}$ and $\mathrm{P}$ were detected from the MAO-treated specimens before immersion in Hanks' solution; however, the amounts were about one-fifth of those detected from the specimens after immersion. In other words, the Ca and P detected by ICP-AES from the MAO-treated specimens containing higher amount of Ag were mainly derived from the newly formed calcium phosphate on their surface. Thus, calcium phosphate formation on TNTZ was considerably accelerated on the oxide layer by MAO treatment even in the presence of Ag with sufficient concentration for eliminating bacteria.

\subsection{Efficacy of Ag Incorporated on TNTZ Surface}

In this study, we confirmed the following two aspects of the Ag incorporated in the resulting surface oxide layer by MAO treatment: (1) It showed excellent antibacterial property against $E$. coli when sufficient $\mathrm{AgNO}_{3}$ was present in the electrolyte for the treatment; and (2) it did not affect the calcium phosphate formation during immersion in simulated body fluid and maintained the superior bioactivity of the MAO-treated surface. Our previous study demonstrated the availability of MAO treatment for improvement of hard-tissue compatibility of TNTZ [13]. From the results obtained in this study, we concluded that antibacterial property could be achieved in addition to hard-tissue compatibility by a simple modification of the treatment condition of the MAO process. This technique may be utilized as a novel surface treatment for development of next-generation implant devices. Nevertheless, the effect of Ag ions dissolved slightly from the oxide layer on living organs or tissues still remains unclear. It is easily supposed that an amount in excess of the appropriate metabolism level of Ag may result in unanticipated adverse effects on a living body. Pratten et al. [28] reported that a low level of Ag ions below $35 \mathrm{ppb}$ was effective as an antimicrobial agent against staphylococcus bacterium. On the other hand, Hardes et al. [29] reported that Ag ions in the blood below 56.4 ppb could be considered as non-toxic in humans. The most important issue to establish a novel process for implants utilizing $\mathrm{Ag}$ as an antimicrobial agent may be how to control the release and accumulation rates of $\mathrm{Ag}$ 
inside the living body. From the viewpoint of these incompatible demands, the behavior of Ag ion released from the oxide layer will be investigated as the next step in this study. In addition, biological testing in vitro and in vivo are also necessary to ensure the biosafety of Ag-containing material surfaces.

\section{Conclusions}

To realize the antibacterial property for TNTZ implants, the formation of a bioactive porous oxide layer containing Ag via MAO treatment was attempted. Incorporation of Ag into the oxide layer as well as $\mathrm{Ca}$ and $\mathrm{P}$ from the electrolyte components during MAO treatment was confirmed. When the electrolyte contained over $0.5 \mathrm{mM}$ of $\mathrm{AgNO}_{3}$, the $\mathrm{MAO}$-treated specimens showed excellent antibacterial property against $E$. coli. In addition, these specimens were completely covered by a thick calcium phosphate layer during immersion in Hanks' solution for 7 days, whereas only a small amount of calcium phosphate formed on untreated TNTZ. Thus, multiple biofunctions such as antibacterial property and bioactivity could be achieved, and this technique was considered to be a promising method to enhance the biocompatibility of TNTZ and other metallic biomaterials made of valve metals.

Acknowledgments: This study was performed under the inter-university cooperative research program of the Institute for Materials Research, Tohoku University.

Author Contributions: Y.T., M. Niinomi, M. Nakai, and H.T conceived and designed the experiments; Y.T., M.S., M.A, and P.C. performed the experiments; Y.T. and H.D. analyzed the data; M. Nakai, and M.S. contributed material preparation; Y.T. wrote the paper.

Conflicts of Interest: The authors declare no conflict of interest.

\section{Abbreviations}

The following abbreviations are used in this manuscript:

TNTZ

Ti-29Nb-13Ta-4.6Zr alloy

MAO Micro-arc oxidation

E. coli Escherichia coli

\section{References}

1. Niinomi, M. Fatigue performance and cyto-toxicity of low rigidity titanium alloy, Ti-29Nb-13Ta-4.6Zr. Biomaterials 2003, 24, 2673-2683. [CrossRef]

2. Hao, Y.L.; Niinomi, M.; Kuroda, D.; Fukunaga, K.; Yang, R.; Suzuki, A. Aging response of the Young's modulus and mechanical properties of Ti-29Nb-13Ta-4.6Zr for biomedical applications. Metall. Mater. Trans. A 2003, 34, 1007-1013. [CrossRef]

3. Niinomi, M.; Hattori, T.; Morikawa, K.; Kasuga, T.; Suzuki, A.; Fukui, H.; Niwa, S. Development of low rigidity $\beta$-type titanium alloy for biomedical applications. Mater. Trans. 2002, 43, 2970-2977. [CrossRef]

4. Suh, J.Y.; Janga, B.C.; Zhu, X.; Ong, J.L.; Kim, K.H. Effect of hydrothermally treated anodic oxide films on osteoblast attachment and proliferation. Biomaterials 2003, 24, 347-355. [CrossRef]

5. Son, W.W.; Zhu, X.; Shin, H.I.; Ong, J.L.; Kim, K.H. In vivo histological response to anodized and anodized/hydrothermally treated titanium implants. J. Biomed. Mater. Res. Part B Appl. Biomater. 2003, 66B, 520-525. [CrossRef] [PubMed]

6. Li, P.; Ducheyne, P. Quasi-biological apatite film induced by titanium in a simulated body fluid. J. Biomed. Mater. Res. A 1998, 41, 341-348. [CrossRef]

7. Hanawa, T. Titanium and Its Oxide Film Substrate for Formation of Apatite. In The Bone-Biomaterial Interface; Davies, J.E., Ed.; University of Toronto Press: Toronto, ON, Canada, 2002; pp. 49-61.

8. Hanawa, T.; Ota, M. Calcium phosphate naturally formed on titanium in electrolyte solution. Biomaterials 1991, 12, 767-774. [CrossRef]

9. Wever, D.J.; Veldhuizen, A.G.; de Vries, J.; Busscher, H.J.; Uges, D.R.A.; van Horn, J.R. Electrochemical and surface characterization of a nickel-titanium alloy. Biomaterials 1998, 19, 761-769. [CrossRef]

10. Hanawa, T.; Okuno, O.; Hamanaka, H. Compositional change in surface of Ti-Zr alloys in artificial bioliquid. J. Jpn. Inst. Met. 1992, 56, 1168-1173. 
11. Ong, J.L.; Lucas, L.C.; Raikar, G.N.; Connatser, R.; Gregory, J.C. Spectroscopic characterization of passivated titanium in a physiologic solution. J. Mater. Sci. Mater. Med. 1995, 6, 113-119. [CrossRef]

12. Hiromoto, S.; Hanawa, T.; Asami, K. Composition of surface oxide film of titanium with culturing murine fibroblasts L929. Biomaterials 2004, 25, 979-986. [CrossRef]

13. Tsutsumi, Y.; Niinomi, M.; Nakai, M.; Tsutsumi, H.; Doi, D.; Nomura, N.; Hanawa, T. Micro-arc oxidation treatment to improve the hard-tissue compatibility of Ti-29Nb-13Ta-4.6Zr alloy. Appl. Surf. Sci. 2012, 262, 34-38. [CrossRef]

14. Ha, J.Y.; Tsutsumi, Y.; Doi, H.; Nomura, N.; Kim, K.H.; Hanawa, T. Enhancement of calcium phosphate formation on zirconium by micro-arc oxidation and chemical treatments. Surf. Coat. Technol. 2011, 205, 4948-4955. [CrossRef]

15. Dibart, S.; Warbington, M.; Su, M.F.; Skobe, Z. In vitro evaluation of the implant-abutment bacterial seal: The locking taper system. Int. J. Oral Maxillofac Implant. 2005, 20, 732-737.

16. Glauser, R.; Schupbach, P.; Gottlow, J.; Hammerle, C.H. Periimplant soft tissue barrier at experimental one-piece mini-implants with different surface topography in humans: A light-microscopic overview and histometric analysis. Clin. Implant. Dent. Relat. Res. 2005, 7, S44-S51.

17. Tesmer, M.; Walle, S.; Koutouzis, T.; Lundgren, T. Bacterial colonization of the dental implant fixture-abutment interface: An in vitro study. J. Periodontol. 2009, 80, 1991-1997. [CrossRef] [PubMed]

18. MacKintosh, E.E.; Patel, J.D.; Marchant, R.E.; Anderson, J.M. Effects of biomaterial surface chemistry on the adhesion and biofilm formation of Staphylococcus epidermidis in vitro. J. Biomed. Mater. Res. A 2006, 78, 836-842. [CrossRef] [PubMed]

19. Ono, M.; Nikaido, T.; Ikeda, M.; Imai, S.; Hanada, N.; Tagami, J.; Matin, K. Surface properties of resin composite materials relative to biofilm formation. Dent. Mater. J. 2007, 26, 613-622. [CrossRef] [PubMed]

20. Meredith, D.O.; Eschbach, L.; Wood, M.A.; Riehle, M.O.; Curtis, A.S.; Richards, R.G. Human fibroblast reactions to standard and electropolished titanium and $\mathrm{Ti}-6 \mathrm{Al}-7 \mathrm{Nb}$, and electropolished stainless steel. J. Biomed. Mater. Res. A 2005, 75, 541-555. [CrossRef] [PubMed]

21. Koerner, R.J.; Butterworth, L.A.; Mayer, I.V.; Dasbach, R.; Busscher, H.J. Bacterial adhesion to titanium-oxy-nitride (TiNOX) coatings with different resistivities: A novel approach for the development of biomaterials. Biomaterials 2002, 23, 2835-2840. [CrossRef]

22. Simonetti, N.N.; Simonetti, G.; Bougnol, F.; Scalzo, M. Electrochemical $\mathrm{Ag}^{+}$for preservative use. Appl. Environ. Microbiol. 1992, 58, 3834-3836. [PubMed]

23. Wassall, M.A.; Santin, M.; Isalberti, C.; Cannas, M.; Denyer, S.P. Adhesion of bacteria to stainless steel and silver-coated orthopedic external fixation pins. J. Biomed. Mater. Res. A 1997, 36, 325-330. [CrossRef]

24. Massè, A.; Bruno, A.; Bosetti, M.; Biasibetti, A.; Cannas, M.; Gallinaro, P. Prevention of pin track infection in external fixation with silver coated pins: Clinical and microbiological results. J. Biomed. Mater. Res. B Appl. Biomater. 2000, 53, 600-604.

25. Tanaka, Y.; Kobayashi, E.; Hiromoto, S.; Asami, K.; Imai, H.; Hanawa, T. Calcium phosphate formation on titanium by low-voltage electrolytic treatments. J. Mater. Sci. Mater. Med. 2007, 18, 797-806. [CrossRef] [PubMed]

26. Kokubo, T.; Takadama, H. How useful is SBF in predicting in vivo bone bioactivity? Biomaterials 2006, 27, 2907-2915. [CrossRef] [PubMed]

27. Yan, Y.; Han, Y.; Lu, C. The effect of chemical treatment on apatite-forming ability of the macroporous zirconia films formed by micro-arc oxidation. Appl. Surf. Sci. 2008, 254, 347-355. [CrossRef]

28. Pratten, J.; Nazhat, S.N.; Blaker, J.J.; Boccaccini, A.R. In vitro attachment of Staphylococcus epidermidis to surgical sutures with and without Ag-containing bioactive glass coating. J. Biomater. Appl. 2004, 19, 47-57. [CrossRef] [PubMed]

29. Hardes, J.; Ahrens, H.; Gebert, C.; Streitbuerger, A.; Buerger, H.; Erren, M.; Gunsel, A.; Wedemeyer, C.; Saxler, G.; Winkelmann, W.; et al. Lack of toxicological side-effects in silver-coated megaprostheses in humans. Biomaterials 2007, 28, 2869-2875. [CrossRef] [PubMed]

(c) 2016 by the authors; licensee MDPI, Basel, Switzerland. This article is an open access article distributed under the terms and conditions of the Creative Commons by Attribution (CC-BY) license (http://creativecommons.org/licenses/by/4.0/). 